\title{
Inschriften auf Stein-Sarkophagen von der Hisardere-Nekropole von Nikaia
}

\author{
Aygün EKINN MERİÇ* - Boris DREYER**
}

\section{1) Das Areal der Hisardere Nekropole der Stadt Nikaia}

Die Nekropole von Hisardere liegt 2,5 km nördlich der modernen Stadt İznik in der Provinz Bursa. Sie befindet sich gleich in der Nachbarschaft des Ortes Hisardere, rund $2 \mathrm{~km}$ östlich des İznik-Sees (Abb. 1). Die Nekropole erstreckt sich über ein etwa 10400 qm großes Areal, in dem Weinreben und Oliven angebaut werden (Abb. 2).

Das Gebiet der Nekropole wurde wegen mehrfacher illegaler Ausgrabungen enteignet und auf der Basis einer Entscheidung der Behörde zum Schutz von Kulturbesitz in Bursa im Jahr 1992 zu einer archäologischen Stätte erster Kategorie erklärt. Im Jahre 2014 wurden die Grenzen des zu schützenden Areals von derselben Behörde genau definiert. Wegen der anhaltenden illegalen Ausgrabungen wurde sodann die Nekropole im Jahre 2018 vom türkischen Ministerium für Kultur und Turismus verstaatlicht.

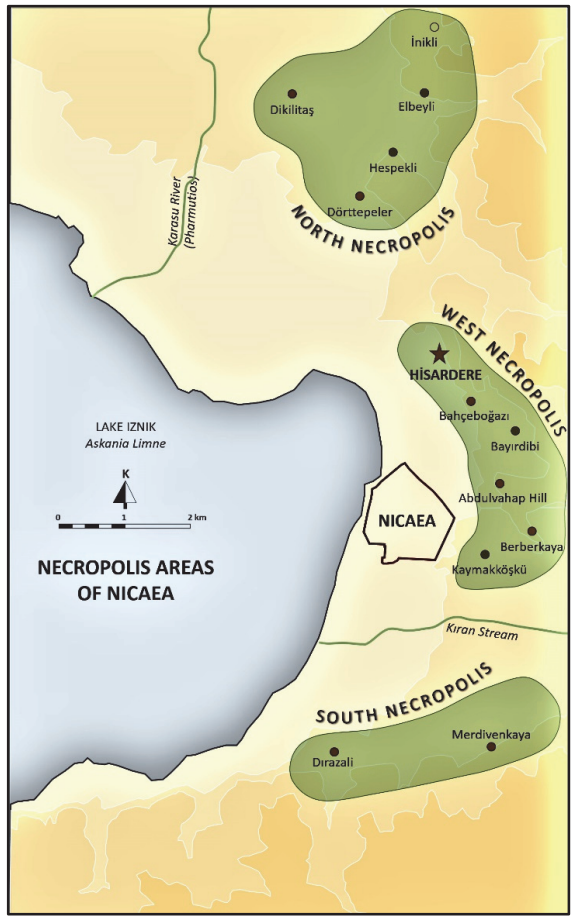

Abb. 1) Hisardere-Nekropole und Umgebung

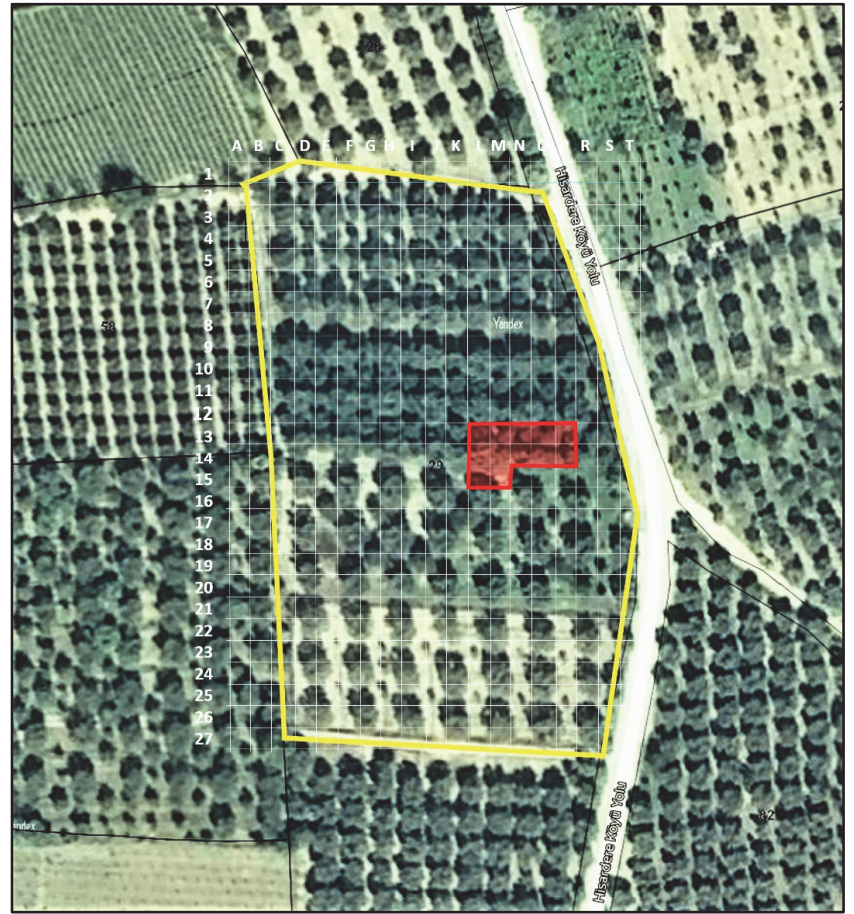

Abb. 2) Luftbild der Nekropole. Das Ausgrabungsgelände ist rot umrandet

* Doç. Dr. Aygün Ekin Meriç, Universität Dokuz Eylül, Fakultät für Human- und Sozialwissenschaften, Fach für Archäologie, İzmir (aygunek@gmail.com; https://orcid.org/0000-0002-1343-847X).

** Prof. Dr. Boris Dreyer, Friedrich-Alexander-Universität Erlangen-Nürnberg (boris.dreyer@fau.de; https://orcid.org/0000-0003-4473-0534; https://www.geschichte.phil.fau.de/department-geschichte/lehrstuehle-und-personen/professur-fuer-alte-geschichte/).

Für wertvolle Hinweise zu den Inschriften danken die Autoren Lukas Müller (Erlangen), die sich insbesondere auch auf das Epigramm beziehen. 
Die illegalen Aktivitäten haben auch zur Auffindung von drei Sarkophagen der Nekropole von Hisardere geführt. Diese Sarkophage konnten jedoch durch die rasche Verlegung in das İznik Museum gerettet werden. Der Sarkophag, der im Jahre 2015 gefunden wurde, gehört dem Sidamara-Typ an ${ }^{1}$. Uns beschäftigen hier allerdings insbesondere der Antigonos-Sarkophag, der 2016 entdeckt wurde, und der Mutter-Tochter-Sarkophag aus dem Jahre 2017 (Abb. 3). Es wurden demnach in der römischen Kaiserzeit Militärbefehlshaber neben wohlhabenden Familien von Nikaia in der Nekropole von Hisardere beigesetzt.

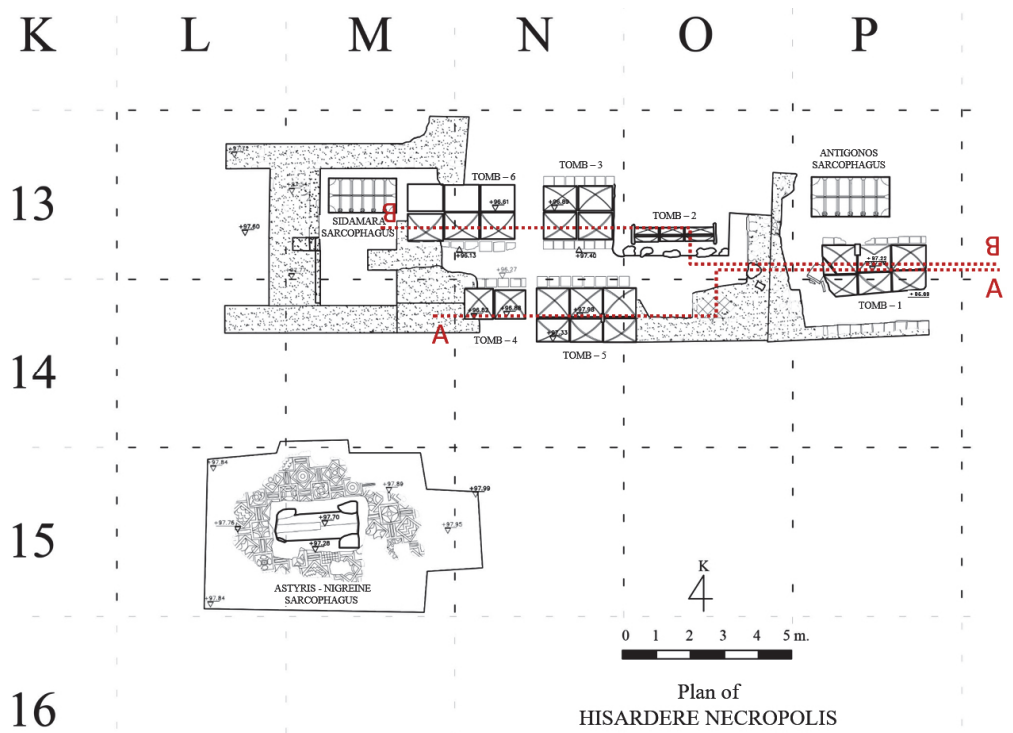

Abb. 3) Plan der Necropole

\section{2) Der Antigonos-Sarkophag und seine Ausgrabung}

\section{2. a) Ausgrabung}

Illegale Ausgräber hatten bereits einen Teil des Sarkophags freigelegt (Abb. 4). Sie hatten bereits eine große Zahl von großen Löchern um den Sarkophag herum gebohrt, um ihn zu lokalisieren. In einem Areal von $5 \times 5 \mathrm{~m}$ begann die Ausgrabung an der Stelle, wo der Deckel des Sarkophags der Oberfläche am nächsten lag. Man stieß sodann auf den Scheitel des Sarkophag-Deckels $0,51 \mathrm{~cm}$ unter der Oberfläche ${ }^{2}$. Auch eine Grabstele südwestlich des Sarkophags tauchte auf.

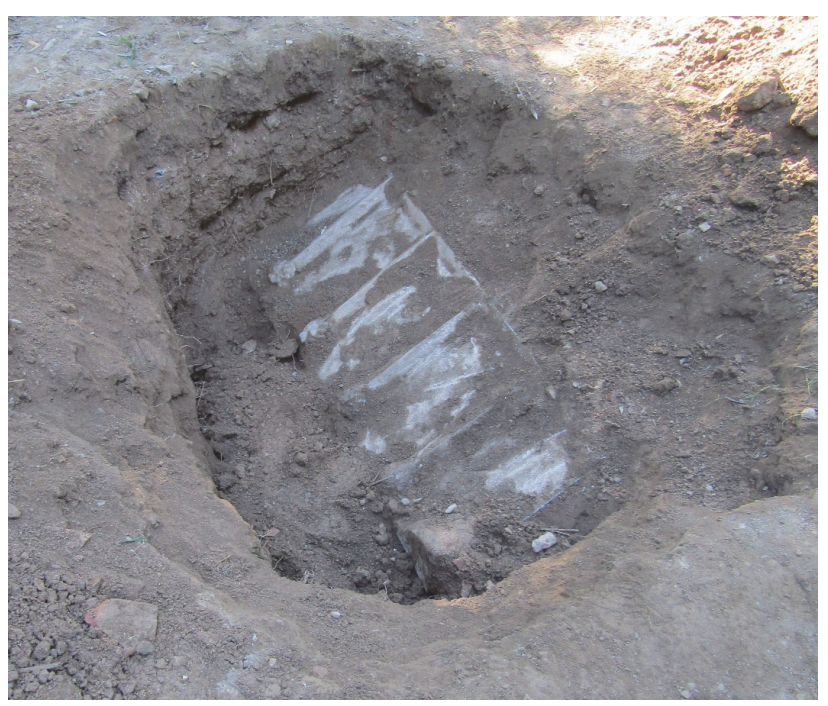

Abb. 4) Der Teil, den die illegalen Ausgräber ausgegraben haben

\footnotetext{
${ }^{1}$ Yaşar 2017, 143, Abb. 1.

${ }^{2}$ Yaşar 2017, 144-145.
} 


\section{2. b) Fragment einer Grabstele}

Die Grabstele ist folglich in der Nekropole zusammen mit dem Antigonos-Sarkophag gefunden worden (Abb. 5). Stelenfragment und Sarkophag stehen aber ansonsten in keinem inhaltlichen Zusammenhang. Jetzt befindet sich die fragmentarische Stele im Garten des Museums von İznik.

Das Fragment ist für die Beschriftung nur nachlässig geglättet worden, es ist überall bestoßen, der Stelenzapfen ist unten gebrochen.

Maße: Höhe (max.) $80 \mathrm{~cm}$; Breite 44,5 cm. Die Buchstabenhöhe beträgt ca. 2,5 cm; die Buchstaben sind teilweise stark verziert (s. z.B. das Alpha am Anfang der drittletzten Zeile). An manchen Stellen ist noch die Originalfarbe (rot) vorhanden, mit denen die Buchstaben ausgemalt waren.

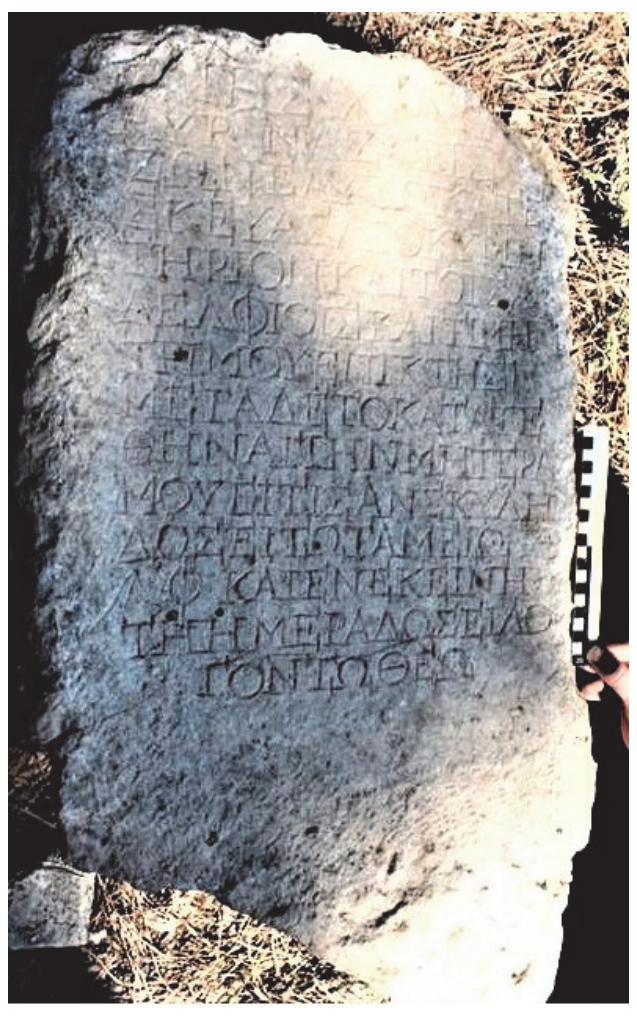

$\operatorname{I\eta } \sigma(o \tilde{\varsigma}) \cdot \mathrm{A} \Omega$

Aủp. Na〈apıৎ

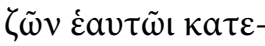

4

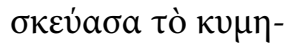

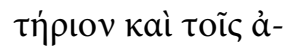

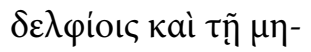

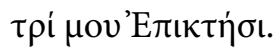

8

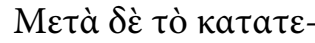

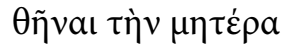

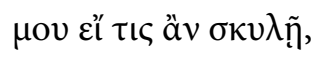

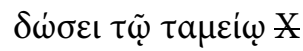

12

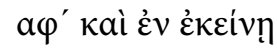

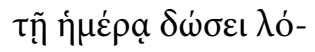

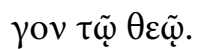

Abb. 5) Grabstele

Übersetzung:

„Jesus - vom Anfang bis zum Ende. Ich, Aurelius Nazaris, habe - noch lebend - für mich selbst das kymeterion gebaut, auch für die Brüderchen und meine Mutter Epiktesis. Wenn einer nach der Beerdigung (die Ruhe) meiner Mutter stört, soll er 1500 Denare an die Staatskasse zahlen und dafür an jenem Tag (des Todes) dem Gott Rechenschaft geben müssen.”

Kommentar:

1: „Ich bin das Alpha und das Omega, der Anfang und das Ende, spricht der Herr, der da ist, der da war und der da kommt, der Allmächtige' (Offb 1,8). Das Alpha und das Omega steht für das genannte Selbstzitat Jesu in der Offenbarung (Johannes). Alpha und Omega, kurz: A und $\Omega$, sind somit ein Symbol für das Umfassende, für den Schöpfer und den Vollender der Welt. Mit 
seiner Liebe begleitet Gott das Leben jedes Einzelnen - das ist seine Zusage und auch sein Trost - vom Anfang bis zum Ende. So verstanden bedeuten Alpha und Omega: Aus meiner Hand kommst du, und in meine Hand nehme ich dich am Ende auch wieder auf. In mir findest du deine Vollendung"'.

2: Der Aureliername verweist die Stele wahrscheinlich in das 3. Jahrhundert. Die Schrift passt

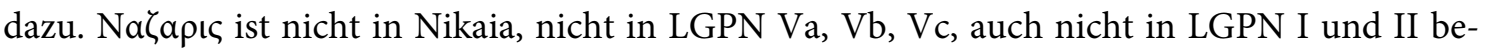
legt, also als Name nicht bekannt ${ }^{4}$.

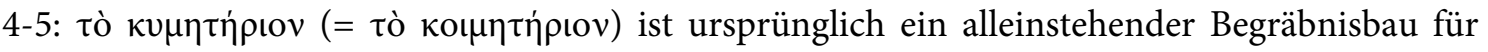
mehrere Personen, später sind es (auch) nach jüdischem Brauch in der christlichen Gemeinde (in Rom) die unterirdischen Begräbnisstätten, nach heutigem Sinn Katakomben ${ }^{5}$. Nach Petzl ist der Begriff erst im 3. Jh. belegt ${ }^{6}$.

7: 'Eлıктท́бเ: zweimal in Nikaia'.

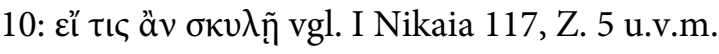

14: Die letzte Zeile ist eingerückt und mittig angeordnet. Die Formel ist häufiger belegt, auch in Nikaia: I Nikaia 556, Z. 11-12.

\section{2. c) Antigonos-Sarkophag}

Nach Bergung des Sarkophags wurde der Deckel wurde unter Aufsicht im Museum geöffnet. Den randvoll mit Wasser gefüllten Sarkophag entleerte man behutsam, bis das Skelett völlig davon befreit war (Abb. 6).

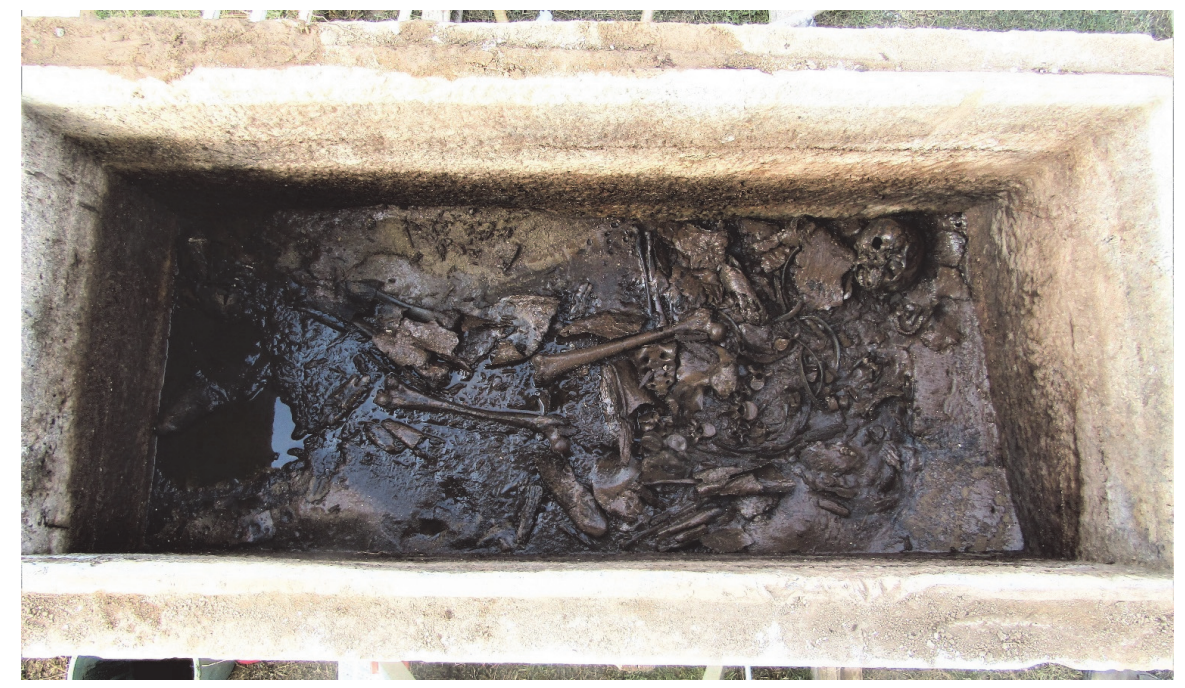

Abb. 6) Ansicht nach dem Ablassen des Wassers im Sarkophag

\footnotetext{
${ }^{3}$ Entnommen der Seite des Erzbistums von Köln (https://www.erzbistum-koeln.de/export/sites/ebk portal/seelsorge_und_glaube/abschied-und-trost/.content/.galleries/downloads/Christliche-SymboleAlpha-und-Omega.pdf; zitiert 17.1.2021).

${ }^{4}$ Auch Zgusta 1964 führten den Namen nicht an.

${ }^{5}$ Ab dem 2. Jh.: Brandenburg 1994, 206-233; Diefenbach 2007.

${ }^{6}$ Petzl 2005, 32.

${ }^{7}$ I.Nikaia II 1372 und Akdoğu Arca 2007, 147-148, no. 3.
} 


\section{2. d) Das Skelett des Antigonos}

Mehrere Holzstücke schwammen im Wasser. Nachdem das Wasser vollständig aus dem Sarkophag entfernt worden war, kamen die Knochen eines menschlichen Skeletts zum Vorschein, die teilweise noch mit Resten von einem beigen Gewebe überzogen waren. Das Skelett und die restlichen Funde im Sarkophag befanden sich aufgrund des Wassers nicht mehr im Verbund und in der originalen Anordnung. Der Anthropologe A. Alpagut vom Museum für Anatolische Zivilisationen ordnete das 1,76 m lange Skelett einem 45-50 Jahre alten Mann $\mathrm{zu}^{8}$. Der In-situZustand des Sarkophags wurde sodann gleich gezeichnet (Abb. 7).

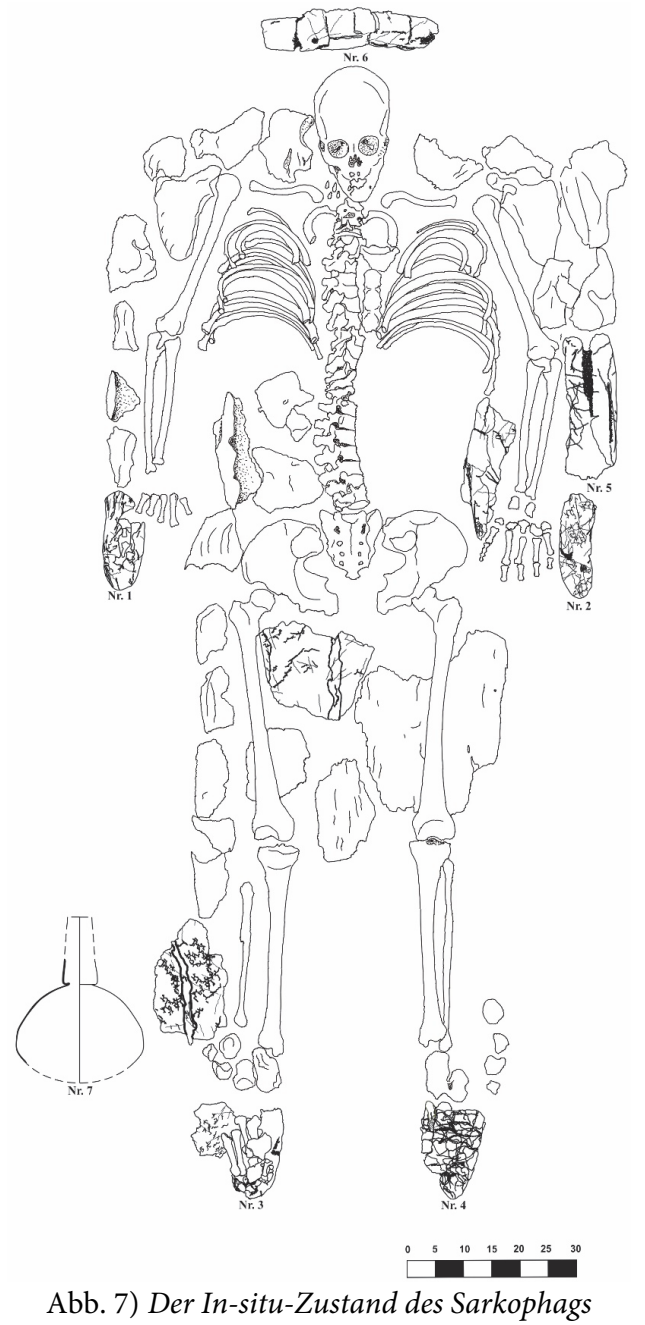

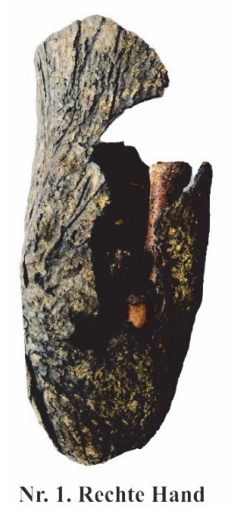

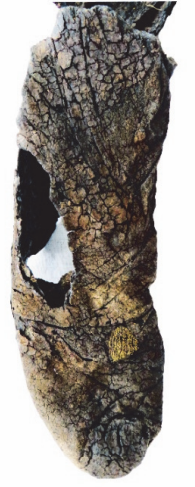

N. 2. Linke Hand

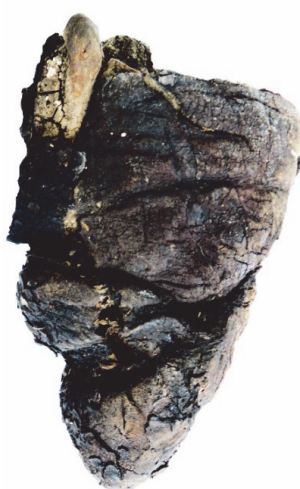

Nr. 3. Rechter Füß

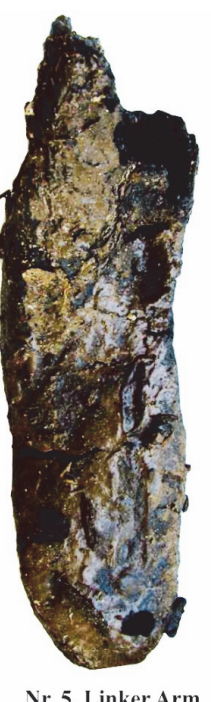

Nr. 5. Linker Arm

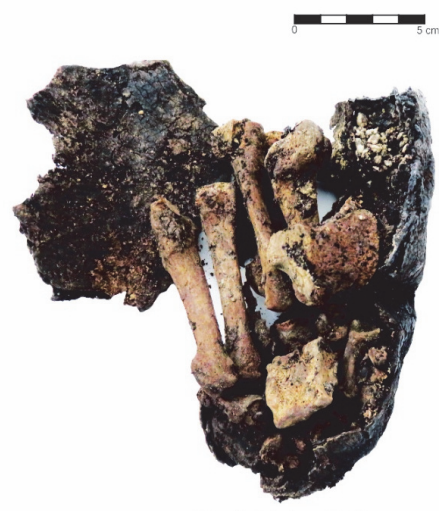

Nr. 4. Linker Füß

Abb. 8) Hand, linker Arm und Füße

In der Folge wurde das Skelett vom Restaurator Y. Dalgıç aus dem regionalen Labor für Restaurierung und Konservierung von Bursa untersucht. Eine schwarze Schicht bedeckte die Stoffe. Die Untersuchungen führten zur Annahme, dass entweder der Stoff nach Einweichen in Teer um den Körper gewickelt wurde oder der Körper in die Stoffe gewickelt wurde, nachdem er mit Teer bedeckt wurde. Nach dem Lösen der Stoffstücke blieben nur Schichten aus gehärtetem Teer und Harz übrig. Nach näherer Betrachtung des Querschnitt der Auflage wurden drei Stofflagen entdeckt. Die Form der Stoffe hat sich am besten an den Händen, am linken Arm und an den Füßen erhalten (Abb. 8). Die um Füße, Hände und den linken Arm gewickelten Stoffstücke

\footnotetext{
${ }^{8}$ Yaşar 2017, 146.
} 
weisen vergoldete Fäden von $1 \mathrm{~cm}$ auf (Abb. 9). Am Fußende wurde ein zerbrochener Glaskrug aus dem dritten Jahrhundert ${ }^{9}$ gefunden (Abb. 10; Abb. 7: Lage des Kruges, Nr. 7). Das in drei Teile unterteilte Holzstück, ungefähr 27-28 cm lang und 5-6 cm dick, sollte als Kissen bzw. Stütze unter dem Kopf dienen (Abb. 11; Abb. 7, Nr. 6). Ein $3 \mathrm{~cm}$ dickes Holzstück war Teil des Holzbettes (Matratze), auf das die Körperteile gelegt wurden (Abb. 11, rechts).

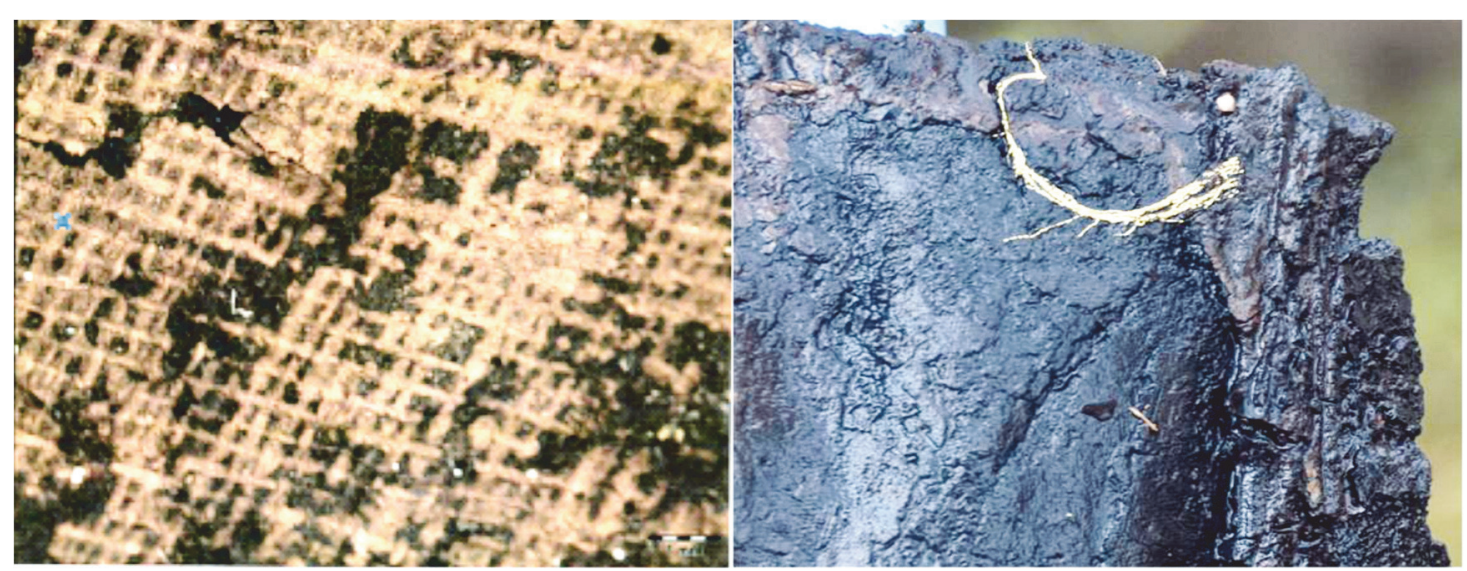

Abb. 9) Detail aus Stoff und Vergoldungsstücken

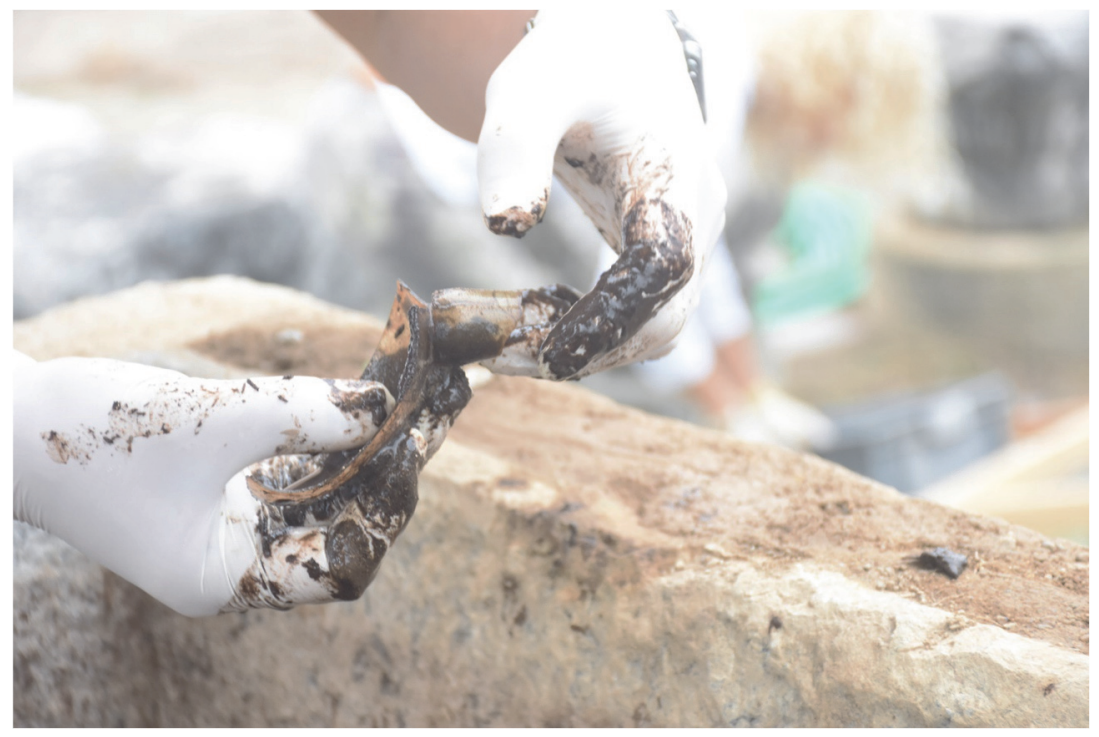

Abb. 10) Glasstücke teilweise zusammengesetzt

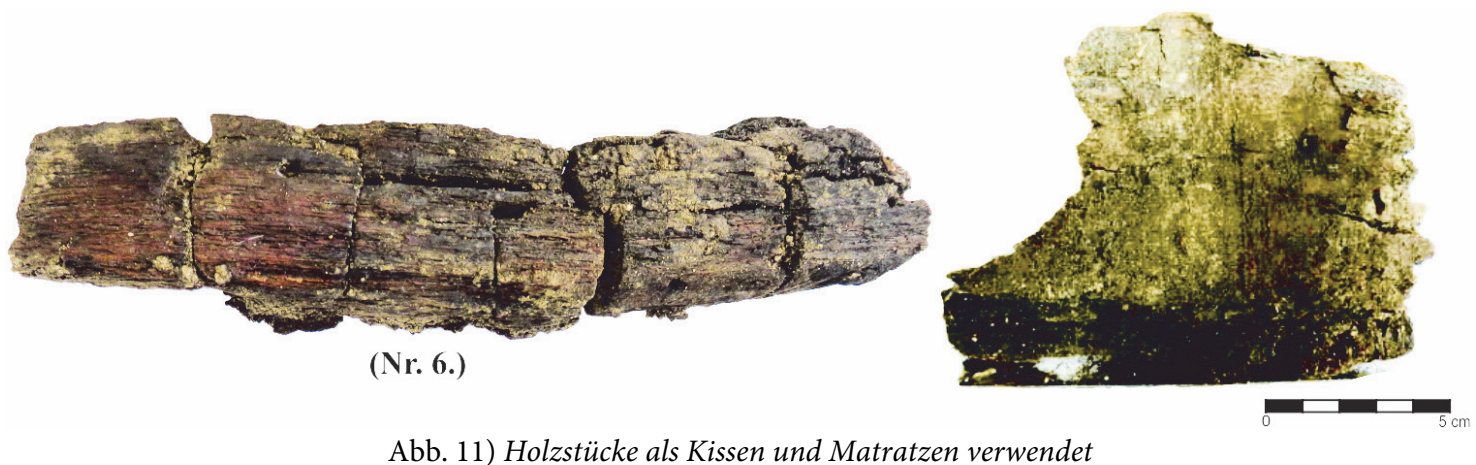

Abb. 11) Holzstücke als Kissen und Matratzen verwendet

${ }^{9}$ Gürler 2000, no. 101 (3. Jh. n.Chr.). 


\section{2. e) Sarkophag (Abb. 12-13.1-5)}

Der Sarkophag steht jetzt im Garten des Museums von İznik. A.A. Altın beschreibt den Sarkophag folgendermaßen ${ }^{10}$ : „Sarkophag mit profilierten Rahmungen und Dachdeckel; blau-grauer Marmor.

Deckel: H: $51 \mathrm{~cm}$; B: 230 cm; T: 116 cm; Kasten: H: 92 cm; B: 226 cm; T: $105 \mathrm{~cm}$

Gelblich verwittert. An der Rückseite ist die linke untere Ecke abgebrochen. Klammerlöcher auf beiden Schmalseiten des Kastens und Deckels.

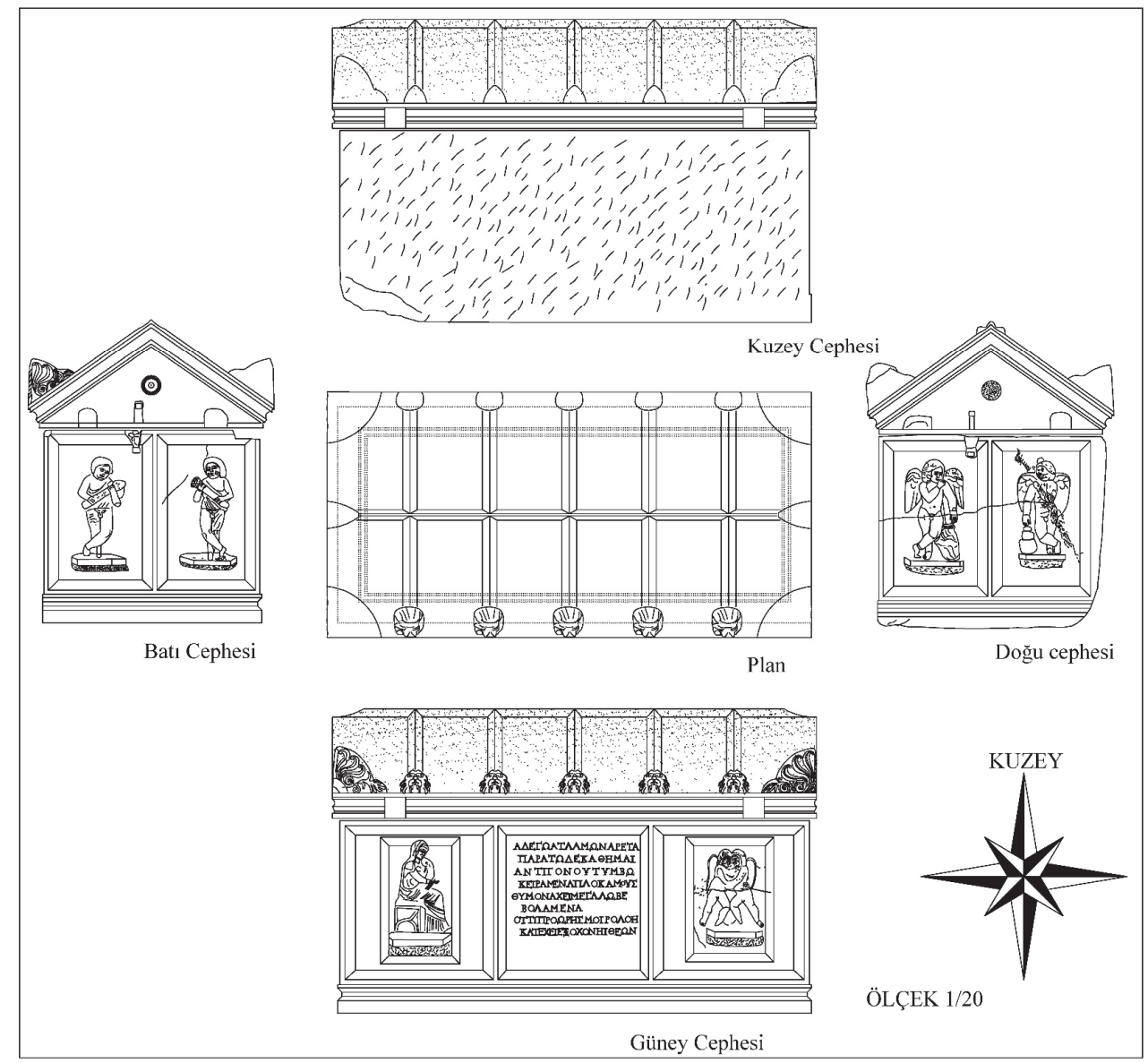

Abb. 12) Zeichungen des Sarcophags

Deckel: Dachdeckel mit Tegulae, Firstziegeln, Löwenkopf-Antefixen und palmettenförmige Eckakroteren. Die Eckakrotere an der hinteren Seite sind undetailliert. In den Giebelfeldern je ein Rundschild. Schräggeisa aus einer Leiste und einem Karnies zwischen zwei schmalen Leisten. Der untere Rand aus einer Leiste. An jeden Seiten befinden sich je zwei Hebebosse (Verf. sic!).

Kasten: Vorderseite (Verf. Abb. 13.1): Vorderseite des Kastens ist in drei Felder eingeteilt. Innerhalb der linken und rechten Bildfelder ist je ein weiterer, kleinerer Rahmen dargestellt, der unten durch einen Sockel begrenzt ist. Im kleineren Rahmen innerhalb des linken Bildfeldes sitzt eine Frau im Typus der "Pudicitia Philista" auf einem Hocker. Sie trägt einen Chiton und ein Himation, mit dem sie ihren Kopf bedeckt. Ihr Kopf ist leicht nach unten gebeugt. Ihr linker

${ }^{10}$ Altın n.d., 153-154, S48, Abb. 73, 74. 
Arm ist senkrecht hochgeführt und sie greift mit der linken Hand an den um Hals gelegten Schleierrand. Ihr rechter Arm liegt auf den Beinen. Im Mittelfeld befindet sich eine achtzeilige griechische Inschrift (Verf. $64 \mathrm{~cm}$ breit und $61 \mathrm{~cm}$ hoch). Innerhalb des rechten Bildfeldes sind zwei ringende Eroten mit Flügeln dargestellt.

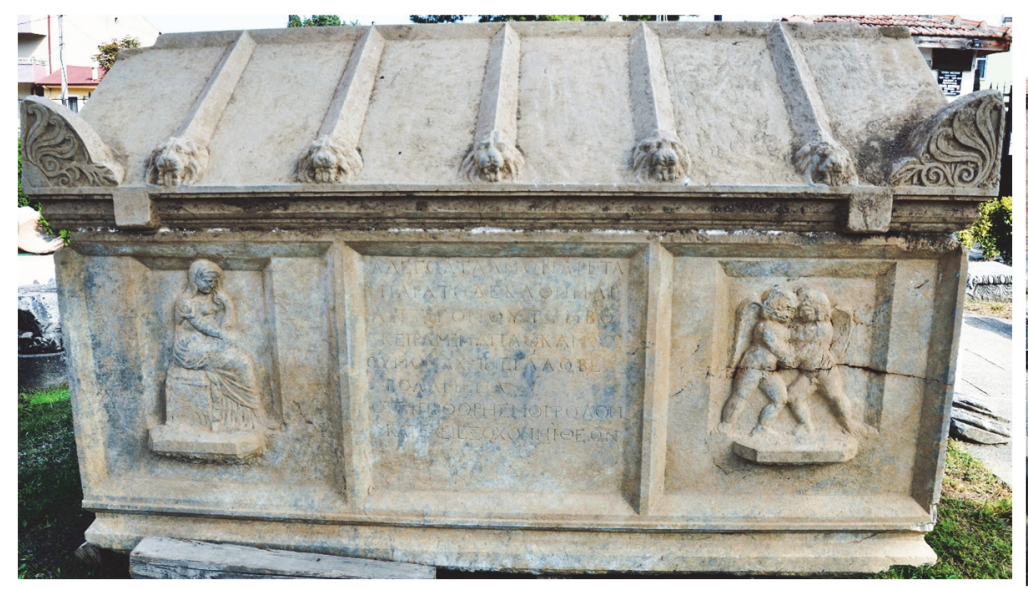

Abb. 13,1) Vorderseite

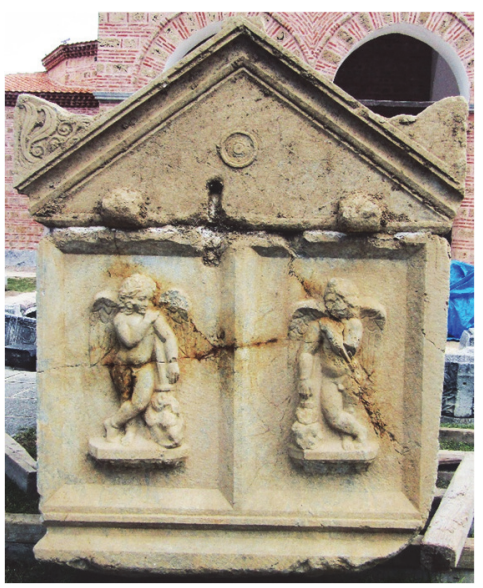

Abb. 13,2) Rechte Schmalseite

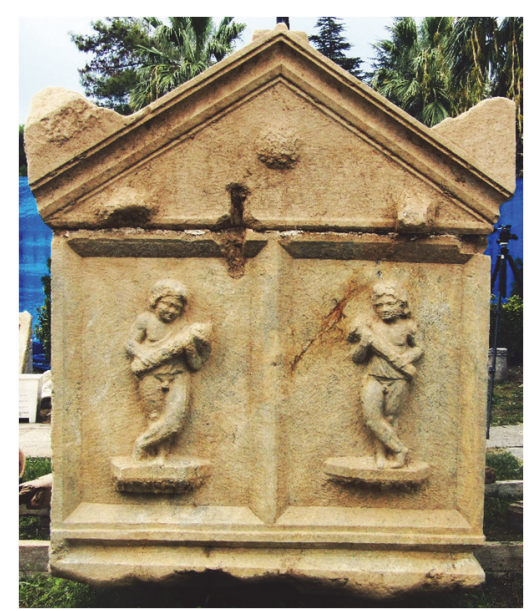

Abb. 13,3) Linke Schmalseite

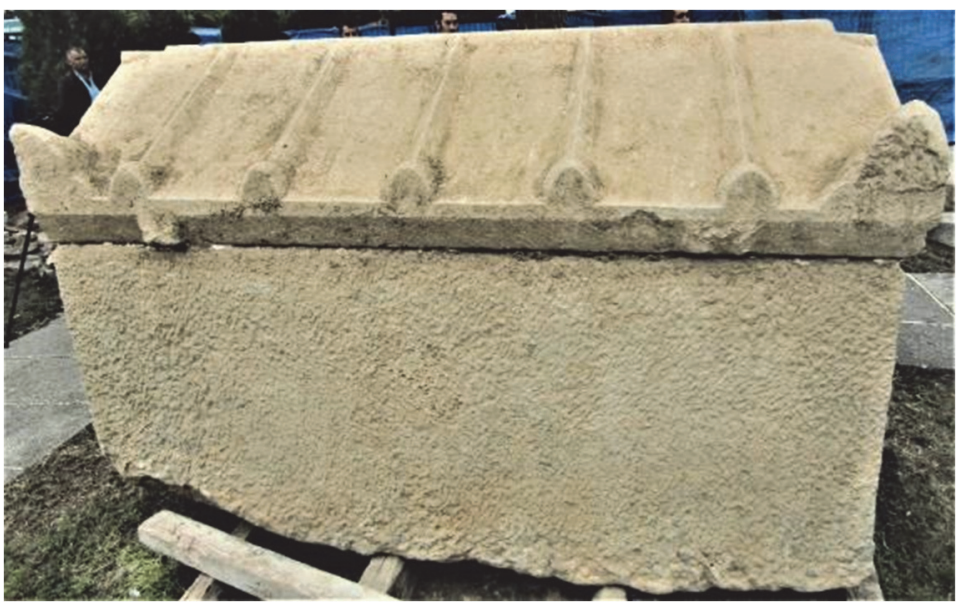

Abb. 13, 4) Rückseite

Rückseite (Verf. Abb. 13. 4): geglättet.

Rechte Schmalseite (Verf. Abb. 13. 2): Diese Seite ist in zwei Felder eingeteilt. In jedem Feld befindet sich ein stehender Eros mit Flügeln und gekreuzten Beinen auf einer Basis. Jeder Eros stützt sich auf eine umgedrehte Fackel. Die Eroten sind antitethisch (Verf. sic!) dargestellt.

Linke Schmalseite (Verf. Abb. 13.3): Diese Seite ist in zwei Felder eingeteilt. In jedem Feld befindet sich ein stehender Knabe auf einer Fußleiste. Jeder trägt einen Fackel mit beiden Händen. Die Knaben sind antitethisch und mit gekreuzten Beinen dargestellt. Jeder Knabe trägt einen kurzen Chiton, die den Oberkörper der Knaben nur teilweise bedeckt haben. Ihre Arme und je eine der Schultern nackt belassen. Datierung: 2.-3. Jh. n.Chr.”.

Die Schrift im Mittelfeld der Längsseite ist sehr klar und gut gestaltet (Abb. 13. 5). Die $3 \mathrm{~cm}$ hohen Buchstaben, die die Inschrift in die Kaiserzeit datieren, weisen Serifen auf.

Der Inhalt der Inschrift korrespondiert mit dem Relief links von der Inschrift mit der verschleierten Frau des Typus „pudicitia philista”, die sich mithin den Kopf in Trauer bedeckt. Das Re- 
lief der Eroten rechts drückt die Liebe, ebenso wie die Knaben und Eroten auf den Schmalseiten aus.

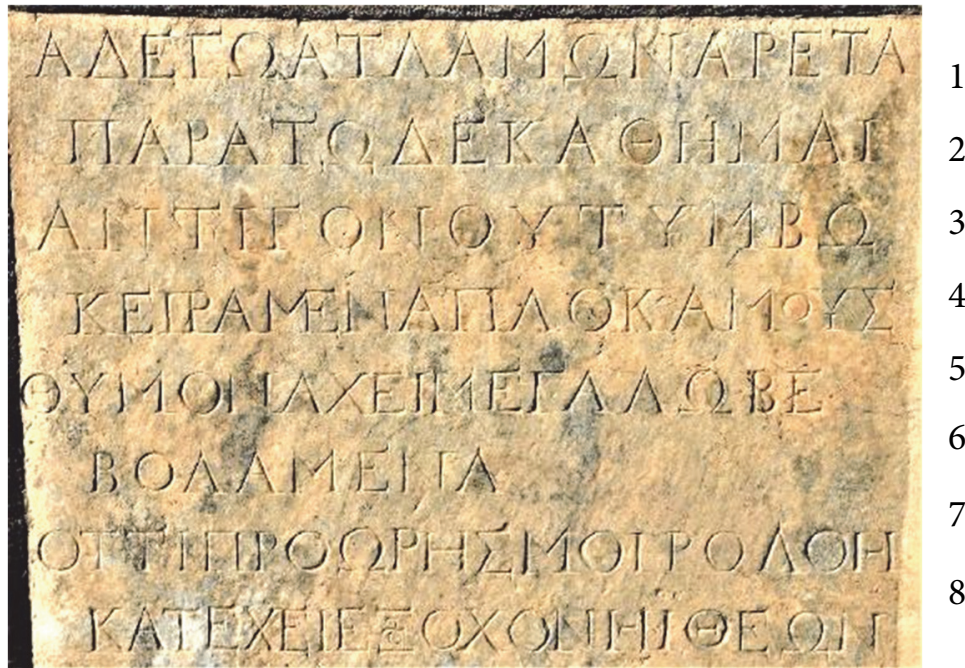

Abb. 13,5) Die Inschrift auf der Vordersite

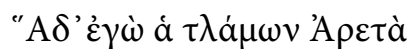

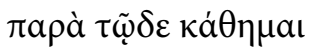

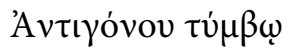

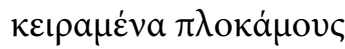

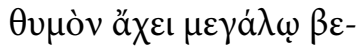

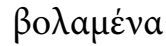

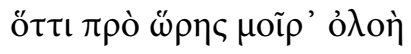

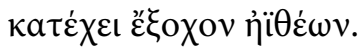
Z. 1-2 Vers 1:

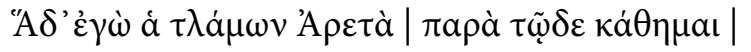
Z. 3-4 Vers 2:

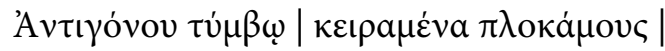
Z. 5-7 Vers 3:

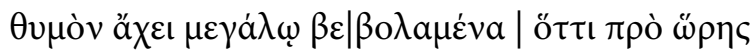
Z. 7-8 Vers 4:

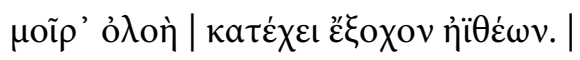

Übersetzung:

„Ich, die traurige Arete, sitze beim Grab des Antigonos, die Locken geschoren, das Herz ist schwer mit Trauer getroffen, dass zu früh die verderbliche Todesgöttin den Hervorragenden unter den Jünglingen in ihren Fängen hält."

\section{Kommentar:}

Die Buchstaben gehören in das 2. bzw. 3. Jh. Damit trifft sich der Befund mit demjenigen zu Sarkophag und Skelett. Viele Epigramme aus dem „Einzugsbereich“ von Nikaia sind erhalten und ediert ${ }^{11}$, verfasst für die unterschiedlichsten Anlässe (Grabmal, Ehren, Weihung, etc.).

$1:$ "A $\delta \varepsilon /$ / H $\delta \varepsilon=$ „Die hier= ich“, mit $\dot{\varepsilon} \gamma \omega \dot{\omega}$,ich hier = ich“ (K-G I 461-462). $\tau \lambda \dot{\alpha} \mu \omega \nu$ dorisch LSJ p. 1800 s.v., unglücklich, elend. - $\dot{\alpha} \tau \lambda \dot{\alpha} \mu \omega v$ A $\rho \varepsilon \tau \alpha^{12}$.

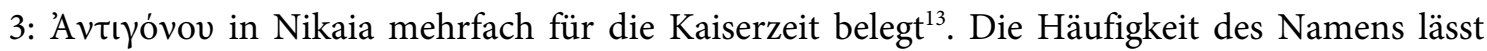
aber keine Zuordnung zu. Gemeinsam haben alle Träger dieses Namens, dass sie gebildet waren.

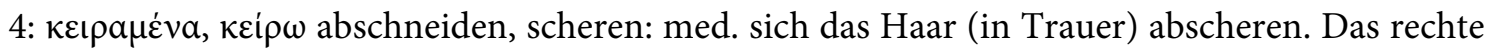
Reliefbild an der linken Schmalseite scheint bildlich als Korrespondenz gedacht zu sein. Wenn

\footnotetext{
${ }^{11}$ Merkelbach - Stauber 2001, 156-199.

${ }^{12}$ Vgl. Merkelbach - Stauber 2001, 162, Nr. 09/05/07 (Nikaia), hier ist Areta kein Name, sondern die

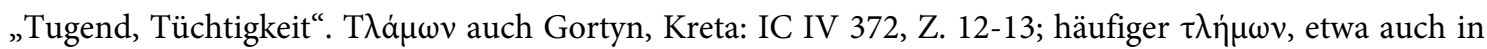
Bithynien: TAM IV 1, 322(2), Z. 7 Nikomedeia (ergänzt).

${ }^{13}$ LGPN Va, p. 35 s.v. Nr. 5 und 6. Darüber handelt I.Nikaia II (3) p. 81-82; Cohn 1894.
} 
das stimmt, dann haben auch die Eroten auf den Reliefs und die jugendlichen Gestalten (s.o.) ihre auf den Text bezogene Bestimmung, zum ersten für die Beziehung zwischen Trauerndem und Betrauertem und zum zweiten mit Bezug auf den Verstorbenen.

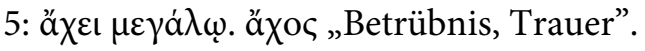

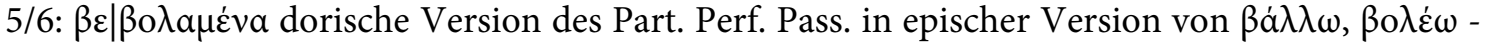
$\beta \varepsilon \beta \dot{\lambda} \lambda \eta \mu$ al, LSJ p. 304, s.v.

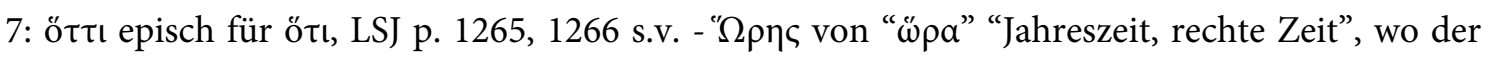
LSJ als ionisches Pendant $̋ \rho \eta$ bietet (LSJ s.v. C). Dies ist ein etabliertes Motiv auch in prosaischen Grabinschriften: z.B. Epidauros IG IV I I 84, Z. 26; unser Antigonos ist älter, aber dennoch „zu früh/vor der Zeit“ gestorben. Parallelen zeigen, dass man noch mit 40-50 Jahren zu dieser Gruppe zählen konnte ${ }^{14}$. - $\mu$ oĩ $\rho$ ' für $\mu$ oĩ $\rho$ a Anteil, Verhängnis, Schicksal, das Schickliche.

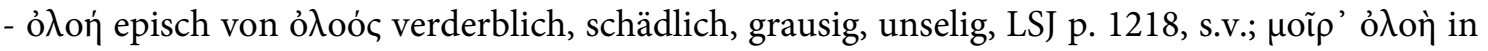
Homer, Il 16, 849; „die verderbliche Todesgöttin“"15. In Epigrammen geläufig: Gortyn, Kreta IC IV 374, Z. 8 (3. Jh. n.Chr.); Lyttos, Kreta IC VI xviii 177, Z. 1 (römische Kaiserzeit); Olympene, Mysien IK 33, Nr. 63, Z. 3-4 (1./2. Jh. n.Chr.); Kyzikene IK 18, Nr. 492, Z. 7 (1. Jh. n.Chr.) u.v.m.

Die Inschrift ist bis Vers 3 ( $\beta \varepsilon \mid \beta o \lambda \alpha \mu \varepsilon \dot{\varepsilon} v \alpha)$ eine wörtliche Übernahme des Grabgedichts auf den telamonischen Ajax von Asklepiades von Samos (Anth. Pal. VII $145=$ Ascl. XXIX G.-P. ${ }^{16}$ ). Statt Ajax ist Antigonos eingefügt.

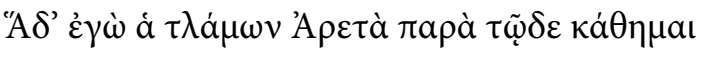

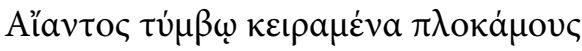

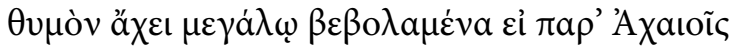

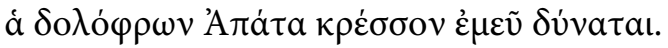

Das Vorbild war als Aufschrift auf eine vermutlich fiktive Statue der Arete, die am Grab des Ajax in Rhoiteion saß, gedacht. Der Dichter unseres Epigramms wechselt ab cỉ in das ionisch-

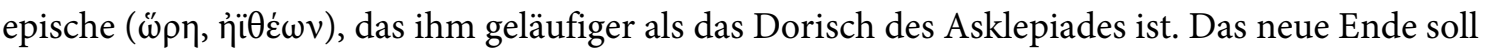
das Epigramm für den konkreten Trauerfall zurechtrücken. Dabei kann er aber die Qualität seines Vorbildes nicht erreichen. Die Metrik ist korrekt, aber mit gehäuften Hiaten. Damit erhebt sich die Frage, woher unser Dichter das hellenistische Grabepigramm auf Ajax aus der Hand des Asklepiades, das immerhin fiktiv in eine nahe Region gehörte, kannte. Unser nicht übermäßig begabter Dichter, der sich gegen Entgelt für gehobenere Ansprüche zur Verfügung stellte, hat wohl auf Sammlungen wie die Anthologia Palatina zurückgreifen können ${ }^{17}$. Der An-

\footnotetext{
${ }^{14}$ Griessmair 1966, 11-14. Antigonos hat sein Leben noch nicht voll ausgekostet.

${ }^{15}$ S. Merkelbach - Stauber 2001, 191, Nr. 09/ 05/42 (Nikaia), Vers 4.

${ }^{16}$ S.a. das kretische Epigramm SEG 16, 532, das auch Asklepiades von Samos entnommen zu sein

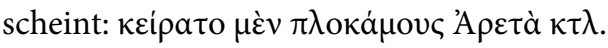

17 Staab 2018, 126-152, bes. 138. Sammelwerke als Stilbücher mit Musterversen scheinen danach wahrscheinlich, wenn auch Zitate hellenistischer Dichter auf Grabinschriften kaum belegt sind, Staab 2018, 113-114.
} 
lass für den Griff zu diesem Epigramm könnte das Relief links von der Inschrift mit der verschleierten Frau der „pudicitia philista” gewesen sein.

\section{3) Sarkophag mit Leichenresten von Mutter und Tochter}

\section{3. a) Ausgrabung}

Die illegalen Ausgräber waren gerade dabei, eine Ecke des Sarkophags zu entdecken, als sie aufgespürt und gefangen gesetzt wurden (Abb. 14). Das İznik-Museum führte daraufhin eine Bergungsgrabung durch und der Sarkophag wurde so gesichert. ${ }^{18}$

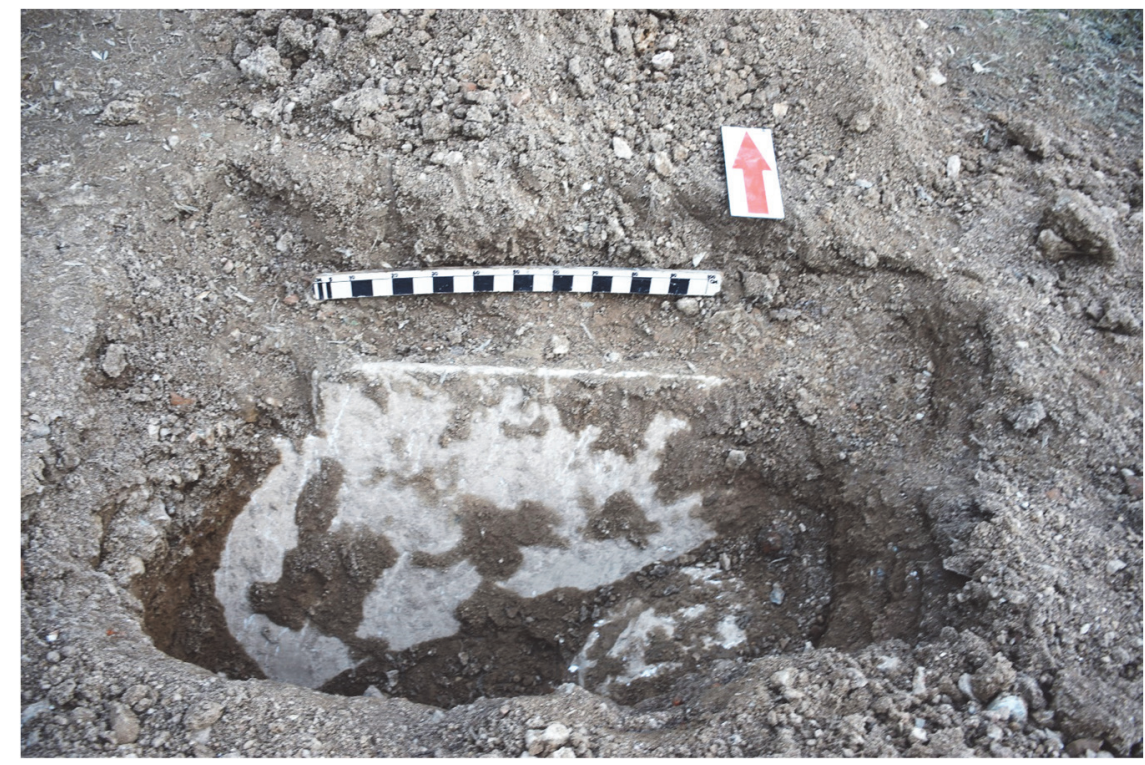

Abb. 14) Der Teil, den die Schmuggler ausgegraben haben

Im Ausgrabungsbereich stieß man 25-30 cm unterhalb der anstehenden Höhe auf ein Mosaik, dessen Schicht sich bis zu dem Bereich erstreckte, in dem sich der Sarkophag befand. Zunächst wurde die Ausgrabung auf 4,5 x 6,5 m begrenzt, die nötig war, um mit der Aufdeckung des Mosaikbodens den Sarkophag zu heben. Das Mosaik setzte sich nach Norden, Süden und Westen nicht fort, es erstreckte sich aber weiter nach Osten (Abb. 15). Es handelt sich um ein geometrisch strukturiertes Mosaik (opus tesselatum) mit den Maßen 7,35 m in der Ost-West Richtung und 4,20 $\mathrm{m}$ in Nord-Süd-Richtung. Es besteht aus roten, grünen, blauen, schwarzen, gelben und weißen Tesserae. Das Mosaik ist in das 4. oder 5. Jahrhundert n.Chr. zu datieren, weil Blumenmotive fehlen, aber Regenbogenmotive vorhanden sind ${ }^{19}$. Für die Ausgrabung des Sarkophags musste der Mosaikboden entfernt werden. Nachdem die Dokumentation und genaue Aufnahme des Mosaiks abgeschlossen war, wurde das Mosaik in acht Portionen gehoben und ins İznik-Museum transportiert ${ }^{20}$.

\footnotetext{
${ }^{18}$ Wir danken der Direktion des Museums für die Unterstützung bei der Rettungsgrabung.

${ }^{19}$ Wir danken Veronika Scheibelreiter-Gail für die Datierung des Mosaiks.

${ }^{20}$ Eren Ertem vom regionalen Labor für Restaurierung und Konservierung von Bursa sowie das Ausgrabungsteam und Restaurierungsfachleute arbeiteten bei der sicheren Entfernung des Mosaiks zusammen.
} 
Als der Mosaikboden in Sicherheit gebracht war, wurde der Sarkophag bis zur Ebene des Deckels mit den Maßen 260x160x105 cm ausgegraben (Abb. 16).

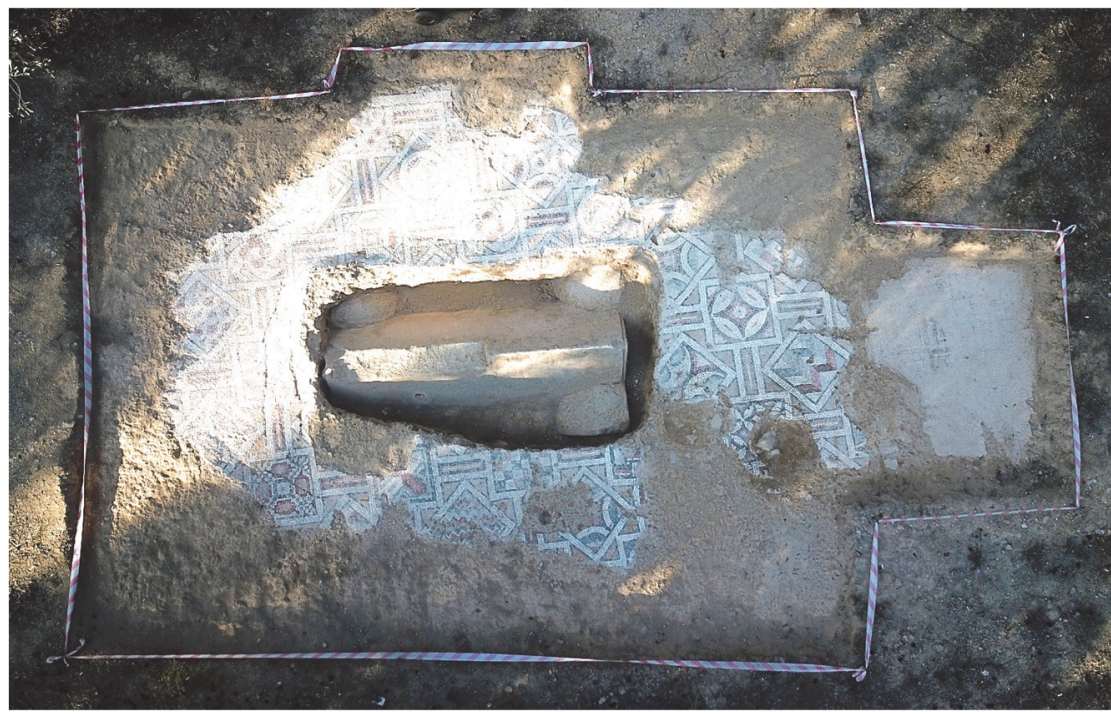

Abb. 15) Mosaikboden auf Sarkophag

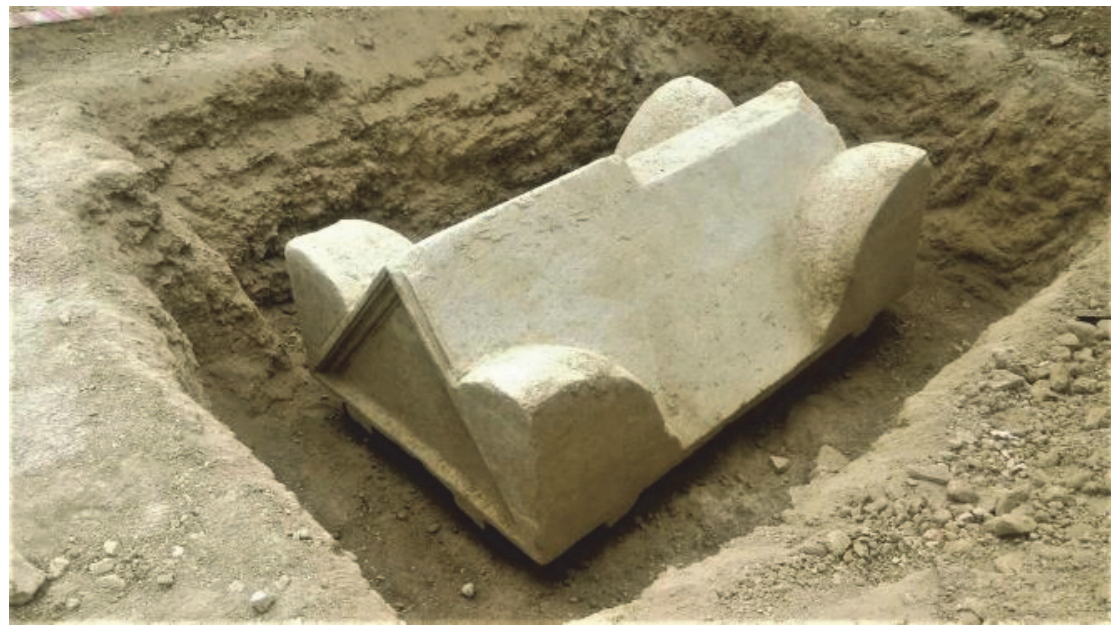

Abb. 16) Sarkophag bis Ebene des Deckels

Der Sarkophag-Deckel wurde mithilfe eines Krans geöffnet. Im Sarkophag waren zwei Personen bestattet, die aneinander geschmiegt in Stoffen eingewickelt waren (Abb. 17). Um die Beschädigung der Skelette zu vermeiden, sollte der Sarkophag an einen sicheren Ort verbracht werden. Daher wurde er auf einen Traktor-Anhänger geladen und zum Museum transportiert (Abb. 18).

\section{3. b) Die bestatteten Personen im Sarkophag}

Im Inneren des Sarkophags befanden sich zwei gut erhaltene Skelette mit Kleidung (Abb. 17, Abb. 19). Die Köpfe der Personen lagen nach Westen orientiert. Die Hände der Person auf der linken Seite lagen verbunden auf dem Becken, die rechte Hand auf ihrer linken. Die Hände der Person zur Rechten waren in derselben Weise arrangiert. Die Bestatteten befinden sich auf hölzernen Planken. Auf der linken Seite befindet sich ein Kissen unter dem Schädel der Person. Das Kissen ist augenscheinlich aus Blumen oder Grass. Die hölzernen Planken unter der Person zur Linken sind durch Holzstücke etwas erhöht. Ali Metin Büyükkarakaya vom Department für 
Anthropologie der Hacettepe Universität konnte folgende erste Resultate über die Skelette präsentieren:

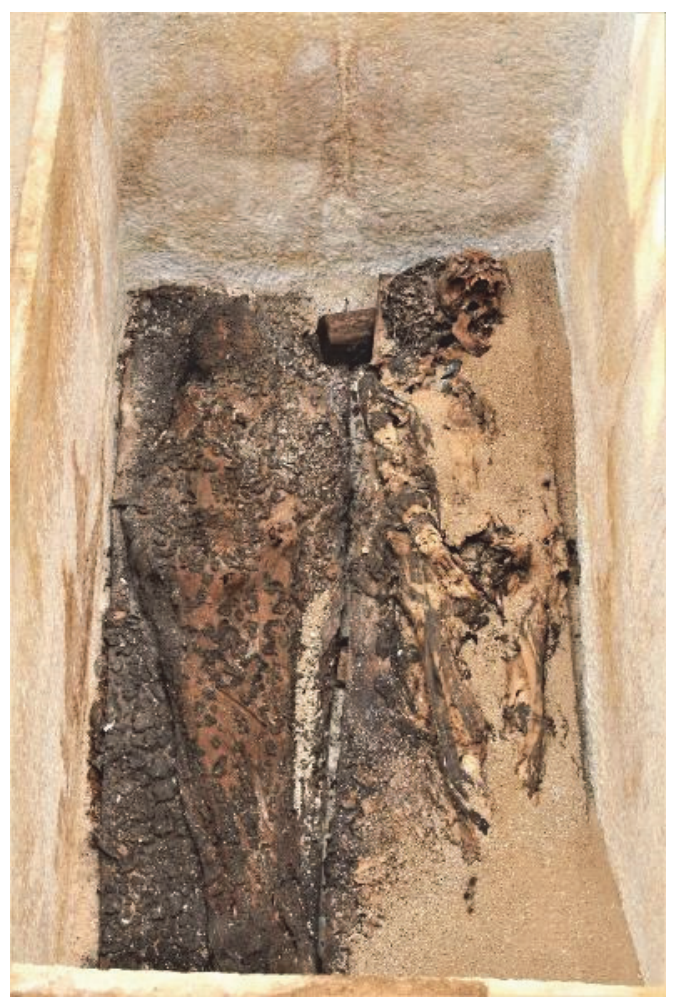

Abb. 17) Im Sarkophag waren zwei Personen bestattet

Ein Skelett im Innern war fast völlig bedeckt (Abb. 17, Abb. 19, Nummer 1). Bei dem anderen Skelett war der Unterkiefer auf den Boden gerutscht und ein Fuß war mit Erde vergraben (Abb. 17, Abb. 19, Nummer 2). Das Becken und die Schädelknochen der Person Nummer 1 geben keine Informationen über das Geschlecht preis. Ihre generelle Erscheinung kann als weiblich interpretiert werden. Das Alter der Person kann aus dem Zustand der Schambeinregion (symphysis pubica) erschlossen werden, die am offenen Teil des Beckens ablesbar ist. Wenn dieser Schluss auch nicht sehr belastbar ist, kann man die Person auf ein Alter von 30 bis 45 Jahre schätzen.

Nach den morphologischen Merkmalen des Schädels handelt es sich bei Nummer 2 sicher um eine Frau. Auf der Grundlage der altermäßigen Veränderungen des Brustbeines kann man das Alter von Nummer 2 auf 24-46 einschätzen. Die Betrachtung der Schambeinregion derselben Person führt zu einer Einschränkung zwischen 25 und 30 Jahren. Die Person Nummer 2 ist daher wohl sehr wahrscheinlich eine junge Erwachsene von etwa 30 Jahren.

Auch die Stoffreste der Kleidung der Bestatteten wurden untersucht: Nach einer Analyse mit dem Fourier-Transform-Infrarotspektrometer (FTIR) bestehen die Kleidungsreste aus Leinen, lokalem Wollstoff und Seide.

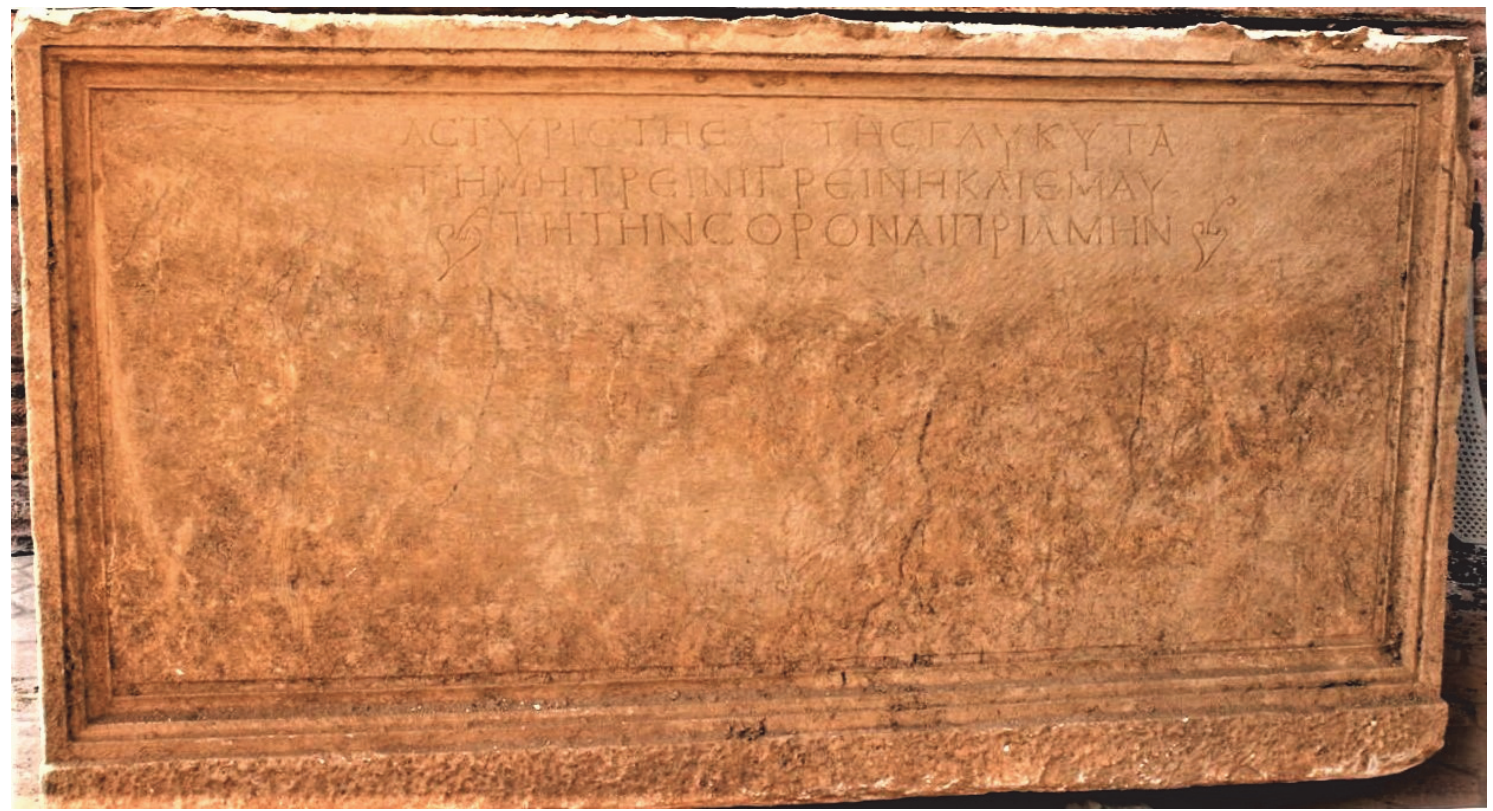


Abb. 18) Sarkophag in İznik Museum

\section{3. c) Sarkophag (Abb. 20)}

Der Kastensarkophag aus blau-grauem Marmor steht jetzt im Garten des Museums von İznik.

Deckel: H: 105 cm; B: 260 cm; T: $160 \mathrm{~cm}$

Kasten: H: $130 \mathrm{~cm}$; B: $246 \mathrm{~cm}$; T: 137,5 cm

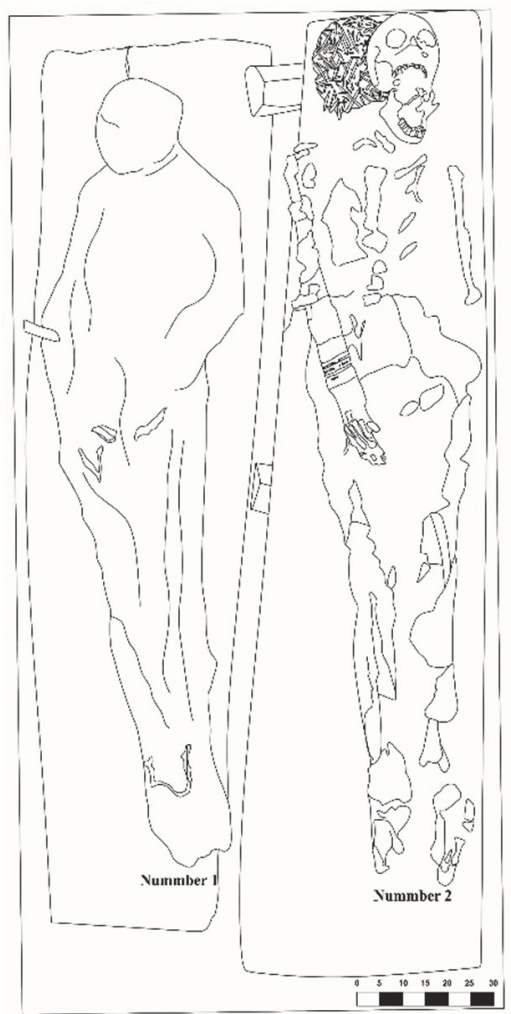

Abb. 19) Der In-situ-Zustand des Sarkophags

Der Steinsarg gehört zum Typ Kastensarkophage und lässt sich gut der Gruppe der bithynischen Sarkophage zuordnen $^{21}$. Der beschriebene Sarkophag ist glatt gearbeitet. Der untere Teil des Sarkophags, der Kasten, hat einen profilierten Rahmen mit scharfen Ecken auf der Frontseite. Im Rahmen befindet sich eine Inschrift mit drei Zeilen. Der Deckel hat einen dreieckigen Giebel (Abb. 16). An beiden Seiten des Giebels befinden sich Eckakrotere. Ein Stück des spitzen Teils der Satteldachabdeckung ist abgearbeitet, vermutlich in der Zeit, als das Mosaik verlegt wurde.

\section{3. d) Inschrift: Sarkophag mit Leichenresten von Mutter und Tochter (Abb. 18)}

Der Sarkophag selbst steht im Museum von İznik in einem klimatisierten Raum, der für die darin erhaltenen Leichenund Stoffreste günstig ist.

Die Maße des Sarkophags sind von der Vorderseite mit Inschrift aus gesehen in der Breite $246 \mathrm{~cm}$, in der Höhe 130 $\mathrm{cm}$ und in der Tiefe 137,5 cm. Die Schrift erstreckt sich auf $128 \mathrm{~cm}$ Breite und in einer Höhe von $24 \mathrm{~cm}$. Die Buchstabenhöhe variiert von 4 bis $6 \mathrm{~cm}$. Die Buchstaben sind mit Serifen versehen und klar gestaltet. Es liegen lautlich bedingte Schreibweisen vor. In der letzten Zeile wurde jeweils am Zeilenanfang und am Zeilenende ein Blattornament eingraviert.

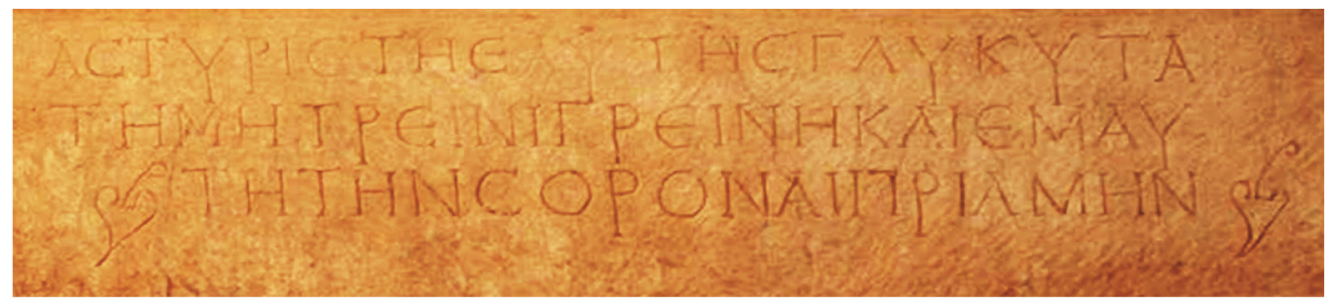

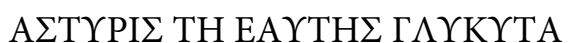

TH MHTPEI NIГPEINH KAI EMAY

ऽTH THN $\Sigma$ OPON AIחPIAMHN ฌ

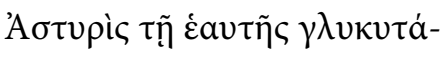

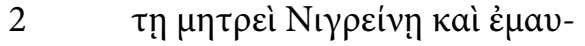

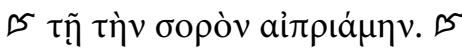

${ }^{21}$ Koch 1993, 29, Abb. 15, 2. 


\section{Übersetzung}

„Ich, Astyris, habe den Sarkophag für meine allerliebste Mutter Nigreine und für mich selbst gekauft."

\section{Kommentar:}

3. Jh. oder später wegen der lunaren Form der Epsila und Sigmata und der orthographischen Schreibweise.

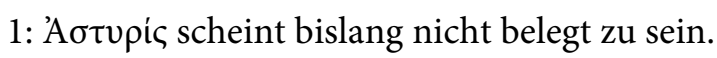

2: $\operatorname{N} \nmid \rho(\varepsilon) \tilde{i} v \alpha$ scheint bisher nicht belegt zu sein; vgl. aber die männliche Form $\mathrm{N} \iota \gamma \rho(\varepsilon) \tilde{\imath} v o \varsigma$ (LGPN II, III.A, V.B und V.C s.v.).

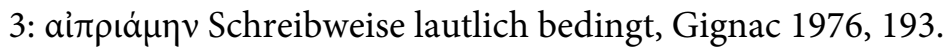

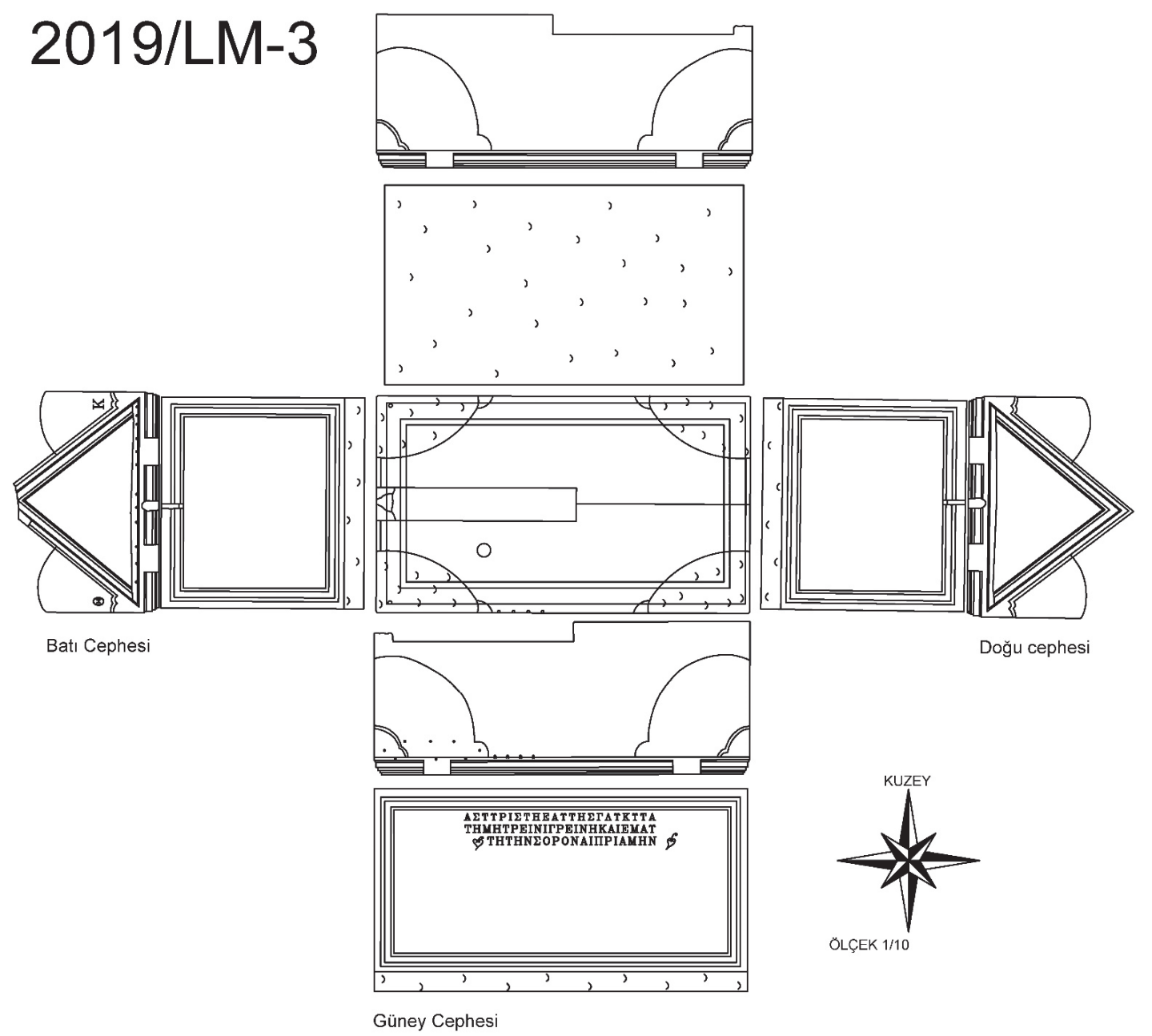

Abb. 20) Ansichts Zeichungen des Sarcophagus 


\section{Bibliographie}

Akdoğu Arca 2007

E. Akdoğu Arca, New Inscriptions From Bithynia, Gephyra 4, 2007, 147-148.

Altın n.d.

A. A. Altın, Die Nekropolen und Grabmäler des Antiken Nikaia in Bithynien (İznik/Türkei), Dissertation Ruhr-Universität Bochum (unveröffentlicht/laufendes Dissertationsprojekt).

Brandenburg 1994 H. Brandenburg, Coemeterium. Der Wandel des Bestattungswesens als Zeichen des Kulturumbruchs der Spätantike, Laverna 5, Scripta Mercaturae, St. Katharinen 1994, 206-233.

Cohn 1894

Diefenbach 2007

L. Cohn, Antigonos (23), in: RE 1, 1894, 2422.

St. Diefenbach, Römische Erinnerungsräume, Heiligenmemoria und kollektive Identitäten im Rom des 3. bis 5. Jahrhunderts n. Chr., Berlin 2007.

Gignac 1976

F. T. Gignac, A Grammar of the Greek Papyri of the Roman and Byzantine Periods, Volume I: Phonology, Mailand 1976.

Griessmair 1966 E. Griessmair, Das Motiv der mors immatura in den griechischen metrischen Grabinschriften, Insbruck 1966.

Gürler 2000

B. Gürler, Tire Müzesi Cam Eserleri, Ankara 2000.

Koch 1993

G. Koch, Sarkophage der römischen Kaiserzeit, Darmstadt 1993.

Merkelbach - Stau-

R. Merkelbach - J. Stauber, Steinepigramme aus dem griechischen Os-

ber 2001 ten, Bd. 2, Die Nordküste Kleinasiens (Marmarameer und Pontos), München-Leipzig 2001.

Petzl 2005

G. Petzl, Neue Inschriften aus Lydien (V), Epigr Anat 38, 2005, 21-34.

Staab 2018

G. Staab, Gebrochener Glanz. Klassische Tradition und Alltagswelt im Spiegel neuer und alter Grabepigramme des griechischen Ostens, Berlin-Boston 2018.

Yaşar 2017

H. Yaşar, Hisardere 2016 Lahit Kurtarma Kazısı, 26. Müze Kurtarma Kazıları Sempozyumu, 143-154, Ankara 2017.

Zgusta 1964

L. Zgusta, Kleinasiatische Personennamen, Prag 1964.

\section{Nikaia'daki Hisardere Nekropolï'nden Taş Lahitler Üzerindeki Yazıtlar Özet}

Makalede İznik’teki (Nikaia) Hisardere Nekropol alanında Hıristiyanlık Dönemi'ne tarihlenen bir yazıt ile birlikte bulunmuş olan ve Roma İmparatorluk Dönemi'ne tarihlenen iki yazıtlı lahit incelenmektedir. Lahitlerden ilki çerçeveli lahit tipindedir ve 45-50 yaşlarında ölen Antigonos'a aittir. Antigonos üç kat yün bir kefene sarılmış ve mezar hediyesi olarak MS 3. yüzyıla tarihlenen bir cam şişe ile birlikte gömülmüştür. Özellikle el ve ayakların kefen içindeki formu bozulmamıştır. Baş altındaki ahşap yastığı ve gövde altındaki ahşap yatağının bir kısmı da korunmuştur. Yazıtında eşi Arete'nin ağzından bir ağıt (epigram) vardır. Sandık tipindeki diğer lahitin içinde yazıtından bir anne ve kızına ait olduğu anlaşılan 30-45 yaşlarında ve 25-30 yaşlarında iki kadın birey vardır. Bireyler keten, yerel yün ve ipekten oluşan kefene sımsıkı sarılmış bir şekilde formları hiç deforme olmadan bulunmuşlardır. Lahtin üzerinde daha geç dönemde yapılmış ve me- 
zarı açmak için kaldırılan MS 4.-5. yüzyıllara tarihlenen bir mozaik zemin bulunmuştur. Lahitlerin her ikisi de soyulmamış olarak, yani gömüldükleri şekilde yaptığımız kazılarla ortaya çıkarılmıştır. Bu lahitler Roma İmparatorluk Dönemi Nikaia’sındaki mezar geleneği hakkında bize yararlı bilgiler sunmaktadır. Ayrıca bu çalışma farklı disiplinler arasındaki işbirliğinin (arkeoloji, antropoloji, epigrafi) nasıl faydalı yeni sonuçlar sunabileceğinin de güzel bir örneği olmuştur.

Yazıtların Türkçe çevirileri şöyledir:

1. Yazıt: İsa (Peygamber) - Başlangıçtan sona kadar. Ben, Aurelius Nazaris henüz hayattayken kendim için ve erkek kardeşlerim ile annem Epiktesis için (bu) kymeterion'u (= koimeterion'u) yaptirdım. Defnedilmesinden sonra birisi annemin (huzurunu) bozacak olursa devlet kasasina 1500 Denaria ödeyecek ve o gün (ölüm günü) Tanriya hesap verecektir!

2. Yazıt: Ben, yaslı Arete, Antigonos'un mezarının başında oturuyorum, buklelerim kesilmiş; yüreğimde büyük bir yas, çünkü kahrolası ölüm Tanrıçası (= kader) gençler içinde olağanüstü olanı vaktinden evvel elinde tutuyor!

3. Yazıt: Ben, Astyris (bu) lahdi çok sevgili annem Nigreine ve kendim için satın aldım.

Anahtar Sözcükler: Nikaia, nekropol, gömü gelenekleri, epigram, Roma İmparatorluk Dönemi.

\section{Inscriptions on stone sarcophagi from Hisardere necropolis in Nikaia}

Abstract

The article examines two sarcophagi with inscriptions found in the necropolis of Hisardere in İznik (Nikaia) and dated to the Roman Imperial Period, together with a funerary stele of a Christian tomb. The first of the sarcophagi belongs to Antigonos, who died at the age of 45-50. Antigonos was wrapped in a three-layered woollen shroud and buried with a glass bottle from the $3^{\text {rd }}$ century $\mathrm{AD}$ as a burial gift. The shroud on the hands and feet in particular is intact. The wooden pillow under the head and part of the wooden bed under the body have also been preserved. The inscription contains Arete's lament, which may be connected to the pictorial programme of the reliefs. In the second sarcophagus lie two female individuals, $30-45$ years old and 25-30 years old, who, as the inscription indicates, are mother and daughter. They were found tightly wrapped in a shroud of linen and local wool and silk. A mosaic from the $4^{\text {th }}-5^{\text {th }}$ century $\mathrm{AD}$ was found on the sarcophagus. This mosaic was removed to open the tomb. The conditions of both sarcophagi are preserved intact. They thus provide us with useful information about the burial traditions of Nikaia in the Roman Imperial Period and are a fine example of how cooperation between disciplines (archaeology, anthropology, epigraphy) can offer fruitful new results.

Keywords: Nikaia, necropolis, funeral traditions, epigram, Roman Imperial Era. 